\title{
Low Temperature Sintering of Aluminum-Zircon Metal Matrix Composite Prepared by Spark Plasma Sintering
}

\author{
Ehsan Ghasali ${ }^{a}$, Hossein Nouranian ${ }^{a}$, Ali Rahbari ${ }^{a}$, Houdsa Majidian ${ }^{a}$, Masoud Alizadeh ${ }^{a *}$, Touradj \\ Ebadzadeh $^{a}$
}

${ }^{a}$ Ceramic Dept, Materials and Energy Research Center, Tehran, Iran

Received: January 18, 2016; Revised: May 24, 2016; Accepted: August 20, 2016

\begin{abstract}
Aluminum-15 wt. \% zircon metal matrix composite was fabricated using spark plasma sintering method at the temperature of $450^{\circ} \mathrm{C}$ and holding time of $4 \mathrm{~min}$. The bending strength of $284 \pm 21 \mathrm{MPa}$ and microhardness of $171 \pm 14$ Vickers were determined for produced composite. XRD investigations proved that almost no decomposition of zircon particles as reinforcement occurred. SEM studies revealed the homogenous dispersion of reinforcement particles in the aluminum matrix.
\end{abstract}

Keywords: Aluminum, Zircon, Sintering, Composite materials

\section{Introduction}

Aluminum metal matrix composites (AMCs) have attractive applications in the field of automotive, aerospace and constructive industries due to their proper properties such as high stiffness, strength and very low weight ${ }^{1,2}$. Previous studies have shown that the addition of hard ceramic particles such as $\mathrm{SiC}, \mathrm{Al}_{2} \mathrm{O}_{3}$, and $\mathrm{TiC}$ could improve the hardness, wear, and abrasion resistance of aluminum alloys. On the other hand, the homogeneous dispersion of reinforcement particles in a metal matrix composite is one of the most important advantages of powder metallurgy compared with casting routs methods ${ }^{3}$. The key step in powder metallurgy process (beside others), is sintering. Spark plasma sintering (SPS) technique is one of the high-technology sintering process that has been used to prepare the large number of composite materials $^{4,5}$. As reported ${ }^{6}$, SPS introduces two important factors in a process of sintering; first is the production of sparks between particles and second is the application of pressure during sintering process. The advantages of SPS method such as rapid heating, surface cleaning of powders, etc, make this process one of the most successful sintering method to obtain fully dense materials ${ }^{7-10}$.

In the present work, the spark plasma sintering technique has been used to produce Al-Zircon composites at a lower sintering temperature compared with conventional method. Additionally, the mechanical properties and microstructure of prepared composites have been investigated.

\section{Materials and method}

Aluminum (1056-merck), zircon (99.5\% purity, average particle size of $5 \mu \mathrm{m}$ ) powders were used as starting materials. Aluminum and zircon (15 wt. \%) powders were mixed in a turbula mixer in ethanol media for 1hours. After mixing,

* e-mail: m-alizadeh@merc.ac.ir the mixtures were dried at $70^{\circ} \mathrm{C}$ to remove ethanol. Then, the dried powders were fed into a circular (30 $\mathrm{mm}$ diameter) graphite die. The sintering was performed at temperature of $450^{\circ} \mathrm{C}$ by applying $10 \mathrm{MPa}$ uniaxial pressure at first step which was increased to $40 \mathrm{MPa}$ at maximum operating temperature and remained for 4 min under vacuum. In order to remove the attached graphite, the surface of sintered samples was ground. After cutting the large samples, the bending strength test was measured on samples with the size $25 \times 5 \times 4 \mathrm{~mm}$. The bulk density of sintered samples was measured using the Archimedes' principle. X-ray diffraction (XRD, Philips X' Pert System) analyses were performed to identify the phases present in the aluminum-zircon composites. Vickers microhardness values were determined using a MKV-h21 Microhardness Tester under a load of $1 \mathrm{~kg}$ for $15 \mathrm{~s}$. Scanning electron microscopy (Sigma / VP, Zeiss) was used to characterize the microstructure of the composites.

\section{Results and discussion}

The XRD pattern of aluminum-zircon composite sintered at $450^{\circ} \mathrm{C}$ (Figure 1) exhibits the sharp peaks of aluminum and zircon as the only crystalline phases which imply that on the precision of XRD analysis no decomposition of zircon and also reaction between aluminum and zircon take place.

Figure 2 demonstrates the displacement and temperature changes versus sintering time and also Figure 3 illustrates the displacement rate as a function of sintering time and temperature. The change and rate of displacement can be used as the criteria of progress in sintering process. The increase in displacement shown in Figure 2 can occur as the result of two important changes in sintering process: 1) increasing sintering temperature and 2) applying pressure at maximum sintering temperature. By changing these two parameters, the amount of displacement as a criterion of densification 


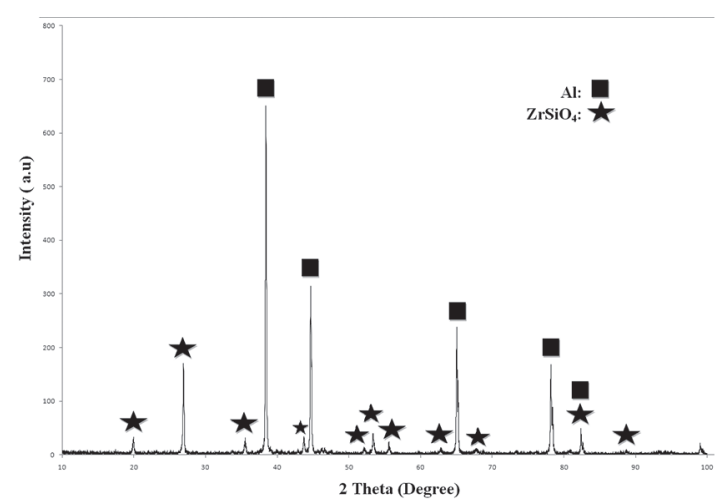

Figure 1: XRD pattern of aluminum-zircon composite sintered at $450^{\circ} \mathrm{C}$.

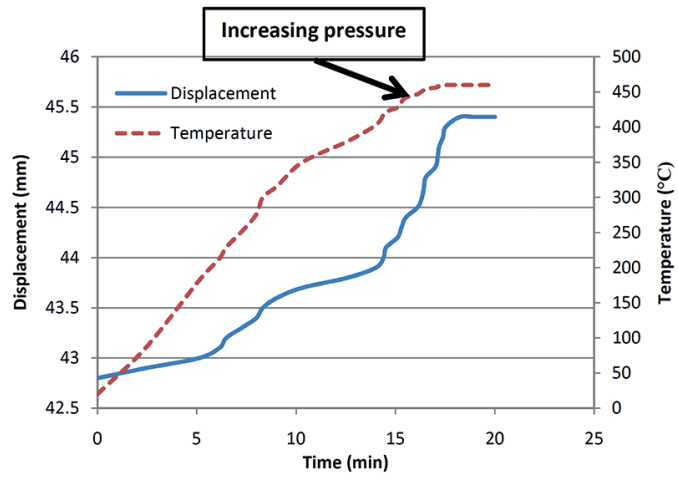

Figure 2: Displacement and temperature changes versus sintering time.

reaches a maximum. The maximum displacement of 2.5 $\mathrm{mm}$ was measured in the present work. It is worth noting that the final stage of sintering process can be distinguished from the constant change of displacement.
Figure 3 shows the displacement rate of sintering procedure for aluminum-zircon composite. There are two important peak areas for displacement rate which demonstrate two main sintering stages.

These areas were labeled in Figure 3 correlated to first and second densification of specimen. The first area correlates the displacement rate to the influence of temperature and also, attributes to gas removal and rearrangement of particles on densification while the second area occurs as pressure increases to $40 \mathrm{MPa}$.

The backscattered electron images and EDS spectra investigations from composite sample (Figure 4) revealed a homogeneous distribution of reinforcement particles in aluminum matrix. The bright spots in backscattered image represent the reinforcement particles, while the dark areas are aluminum matrix (spot 3 in Figure 4). Spot 1 introduces the existence of aluminum, zirconium, silicon and oxygen elements; this combination of elements shows most likely the existence of zircon and aluminum particles, as XRD pattern of Figure 1 confirms. It is noticeable that in EDS spectra shown in Figure 4 a peak of carbon is observable; it is because of using carbon foils in sintering process, therefore accelerated diffusion of carbon atoms into the aluminum matrix occurs under the SPS conditions.

Table 1 presents relative density, bending strength and microhardness values of prepared composite. A highly dense aluminum-zircon composite was obtained by the present work. The bending strength and microhardness of $284 \pm 21$ $\mathrm{MPa}$ and $171 \pm 14$ Vickers, respectively, were measured for sintered samples. The mechanical results obtained by our work are in good agreement with other published results in the field of aluminum-zircon composite. H. Abdizadeh et $\mathrm{l}^{11}$ reported the production of aluminum-zircon composite through powder metallurgy by sintering at $600^{\circ}$ and $650^{\circ} \mathrm{C}$
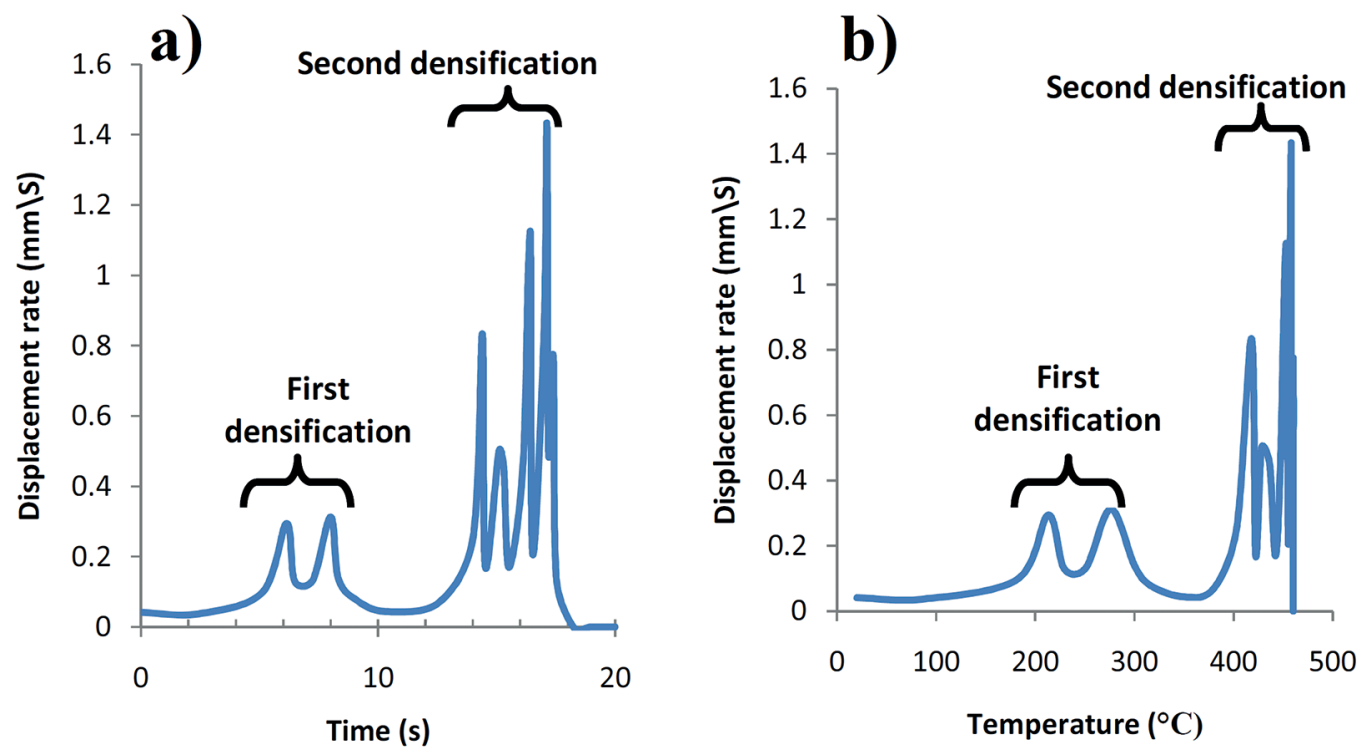

Figure 3: Displacement rate Vs time and temperature in sintering process. 

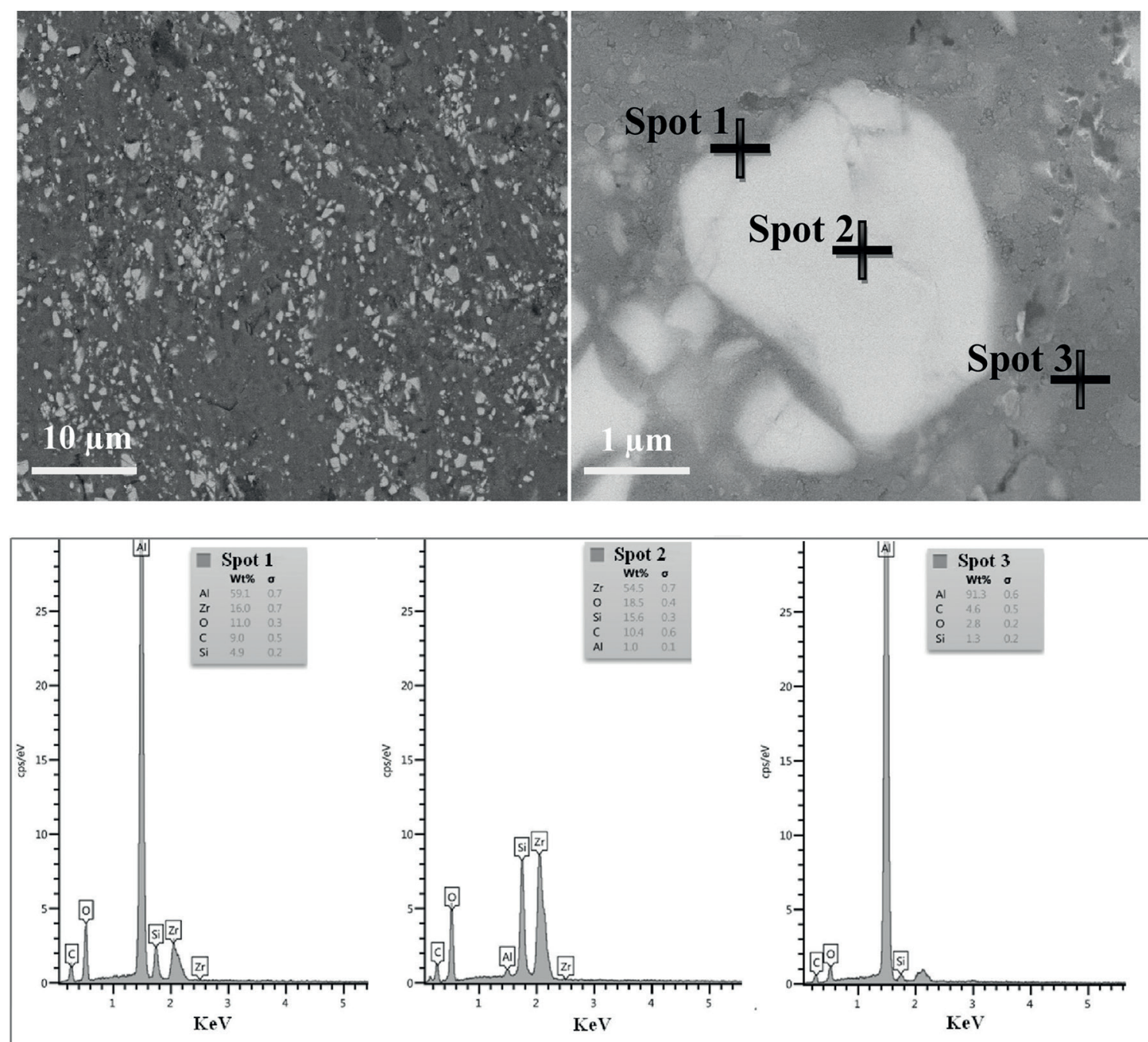

Figure 4: SEM images and EDS spectra of aluminum-zircon composite.

for $65 \mathrm{~min}$. The reported relative density and mechanical properties of their work are almost lower than those reported in the present work due to the lower sintering time and temperature during SPS process beside application pressure during sintering process. The mentioned advantages of SPS process yield to better mechanical properties in lower sintering time and temperature.

Table 2 presents mechanical properties and relative density ofAl-Zircon composite which investigated by other researchers. As it can be seen in Tables 1 and 2, the mechanical and relative density results of these investigations are higher than other researcher's works. Application of spark plasma sintering leads to near fully dense Al-Zircon composite with proper microstructure. The lower sintering time and temperature beside PM technique leads to enhanced properties of composite. The capabilities of SPS method for preparation of aluminum matrix composite with unique properties have been reported by researchers ${ }^{16-18}$.

\section{Conclusions}

Aluminum-zircon composite has been prepared through spark plasma sintering method as a novel technique at a low sintering temperature $\left(450^{\circ} \mathrm{C}\right)$. A highly dense aluminum composite with proper mechanical properties (the bending strength of $284 \pm 21 \mathrm{MPa}$ and microhardness of $171 \pm 14$ Vickers) were obtained by SPS method. Application of SPS could result in producing of aluminum-zircon composite with uniform microstructure and suitable mechanical properties.

Table 1: Relative density, bending strength and microhardness of prepared composite.

\begin{tabular}{lccc}
\hline properties & Relative density $(\%)$ & Bending strength (MPa) & Microhardness (Vickers) \\
\hline Al-Zircon composite & $99.3 \pm 5$ & $284 \pm 21$ & $171 \pm 14$ \\
\hline
\end{tabular}


Table 2: Mechanical properties and relative density of Al-Zircon composite investigated by other researchers.

\begin{tabular}{|c|c|c|c|c|c|}
\hline samples & Method & hardness & Relative density & Tensile Strength & Ref \\
\hline $\begin{array}{l}\mathrm{Al}-4.5 \% \mathrm{Cu} / \mathrm{Zircon} \\
\text { sand }\end{array}$ & $\begin{array}{l}\text { Casting-quenching- } \\
\text { aging }\end{array}$ & 74 vickers & - & - & A. Sharma ${ }^{12}$ \\
\hline Al-5wt $\%$ Zircon & Casting & 75 brinell & - & $220 \mathrm{MPa}$ (UTS) & H. Abdizadeh ${ }^{13}$ \\
\hline Al-10vol\%Zircon & $\begin{array}{l}\text { PM-Conventional } \\
\text { sintering }\end{array}$ & 60 brinell & $89 \% \mathrm{TD}$ & $\begin{array}{l}160 \mathrm{MPa} \text { (yield } \\
\text { stress) }\end{array}$ & H. Abdizadeh ${ }^{11}$ \\
\hline $\begin{array}{l}\text { Al-13.5Si-2.SMg } \\
-15 \text { vol\%Zircon }\end{array}$ & $\begin{array}{l}\text { PM-Conventional } \\
\text { sintering }\end{array}$ & 106 vickers & $88 \% \mathrm{TD}$ & $\begin{array}{c}50 \mathrm{MPa} \text { (YS)-86 } \\
\mathrm{MPa} \text { (UTS) }\end{array}$ & J.U. Ejiofor ${ }^{14}$ \\
\hline $\begin{array}{l}\text { Al-13.5Si-2.SMg } \\
-15 \text { vol\%Zircon }\end{array}$ & $\begin{array}{l}\text { Casting Figure } \\
\text { 3. Displacement } \\
\text { rate Vs time and } \\
\text { temperature in } \\
\text { sintering process. }\end{array}$ & 75 brinell & - & $190 \mathrm{MPa}$ (UTS) & K. Shirvanimoghaddam ${ }^{15}$ \\
\hline
\end{tabular}

\section{References}

1. Surappa MK. Aluminium matrix composites: Challenges and opportunities. Sādhanā. 2003;28(1):319-334.

2. Das S, Udhayabanu V, Das S, Das K. Synthesis and characterization of zircon sand/Al- $4.5 \mathrm{wt} \% \mathrm{Cu}$ composite produced by stir casting route. Journal of Materials Science. 2006;41(14):4668-4677.

3. Geni M, Kikuchi M. Damage analysis of aluminum matrix composite considering non-uniform distribution of $\mathrm{SiC}$ particles. Acta Materialia. 1998;46(9):3125-3133.

4. Mamedov V. Spark plasma sintering as advanced PM sintering method. Powder Metallurgy. 2002;45(4):322-328.

5. Tokita M. Development of large-size ceramic/metal bulk FGM fabricated by spark plasma sintering. Materials Science Forum. 1999;308-311:83-88.

6. M Suárez A, Fernández JL, Menéndez R, Torrecillas HU, Kessel J, Hennicke R, et al. Challenges and Opportunities for Spark Plasma Sintering: A Key Technology for a New Generation of Materials. In: Ertuğ B, ed. Sintering Applications. Rijeka: InTech; 2013. doi: 10.5772/53706.

7. Xie GQ. Sintering process and interfaces microstructure of metal powders by pulse electric current sintering. [PhD Thesis]. Niigata: Niigata University; 2003.

8. Omori M. Sintering, consolidation, reaction and crystal growth by the spark plasma system (SPS). Materials Science \& Engineering: A. 2000;287(2):183-188.

9. Ghasali E, Alizadeh M, Ebadzadeh T. Mechanical and microstructure comparison between microwave and spark plasma sintering of Al- $\mathrm{B}_{4} \mathrm{C}$ composite. Journal of Alloys and Compounds. 2016;655:93-98

10. Ghasali E, Pakseresht A, Safari-kooshali F, Agheli M, Ebadzadeh $\mathrm{T}$. Investigation on microstructure and mechanical behavior of $\mathrm{Al}-\mathrm{ZrB}_{2}$ composite prepared by microwave and spark plasma sintering. Materials Science \& Engineering: A. 2015;627:27-30.
11. Abdizadeh H, Ashuri M, Moghadam PT, Nouribahadory A, Baharvandi R. Improvement in physical and mechanical properties of aluminum/zircon composites fabricated by powder metallurgy method. Materials \& Design. 2011;32(8-9):4417-4423.

12. Sharma A, Das S. Study of age hardening behavior of Al-4.5 wt $\% \mathrm{Cu} /$ zircon sand composite in different quenching media $-\mathrm{A}$ comparative study. Materials and Design. 2009;30(9):3900-3903.

13. Abdizadeh H, Baharvandi HR, Shirvani Moghaddam K. Comparing the effect of processing temperature on microstructure and mechanical behavior of $\left(\mathrm{ZrSiO}_{4}\right.$ or $\left.\mathrm{TiB}_{2}\right) /$ aluminum composites. Materials Science and Engineering: A. 2008;498(1-2):53-58.

14. Ejiofo JU, Okorie BA, Reddy RG. Powder processing and properties of zircon-reinforced Al-13.5Si-2,5Mg alloy composites. Journal of Materials Engineering and Performance. 1997;6(3):326-334.

15. Shirvanimoghaddam K, Khayyam H, Abdizadeh H, Karbalaei Akbari M, Pakseresht AH, Abdi F, et al. Effect of $\mathrm{B}_{4} \mathrm{C}, \mathrm{TiB}_{2}$ and $\mathrm{ZrSiO}_{4}$ ceramic particles on mechanical properties of aluminium matrix composites: Experimental investigation and predictive modelling. Ceramics International. 2016;42(5):6206-6220. doi: http://dx.doi.org/10.1016/j.ceramint.2015.12.181.

16. Ghasali E, Pakseresht A, Rahbari A, Eslami-shahed H, Alizadeh M, Ebadzadeh T. Mechanical properties and microstructure characterization of spark plasma and conventional sintering of Al-SiC-TiC composites. Journal of Alloys and Compounds. 2016;666:366-37.

17. Saheb N, Iqbal Z, Khalil A, Hakeem AS, Al Aqeeli N, Laoui $\mathrm{T}$, et al. Spark plasma sintering of metals and metal matrix nanocomposites: a review. Journal of Nanomaterials. 2012;2012:983470.

18. Saheb N. Spark plasma and microwave sintering of Al6061 and A12124 alloys. International Journal of Minerals, Metallurgy, and Materials. 2013;20(2):152-159. 